\section{Influence of Daily Light Period and Irradiance on Yield and Leaf Elemental Concentration of Hydroponically Grown Sweetpotato}

\author{
Desmond G. Mortley ${ }^{1,4}$, Stephanie Burrell ${ }^{2}$, Conrad K. Bonsi ${ }^{3}$, \\ Walter A. Hill ${ }^{3}$, and Carlton E. Morris ${ }^{3}$ \\ Center for Food and Environmental Systems for Human Exploration of Space \\ and G.W. Carver Agricultural Experiment Station, Tuskegee University, \\ Tuskegee, AL 36088
}

Additional index words. Ipomoea batatas, light intensity, nutrient film technique, soilless culture

\begin{abstract}
Growth chamber experiments were conducted to evaluate the effect of irradiance and daily light period on storage root yield and leaf elemental concentration of two sweetpotato cultivars grown hydroponically by use of the nutrient film technique (NFT). Stem cuttings $(15 \mathrm{~cm})$ of $\mathrm{cv}$. Whatley/Loretan and Georgia Jet were grown in NFT channels $(0.15 \times 0.15 \times 1.2 \mathrm{~m})$ in reach-in growth chambers under light period/irradiance combinations of $18 \mathrm{~h}: 300 \mu \mathrm{mol} \cdot \mathrm{m}^{-2} \cdot \mathrm{s}^{-1}$ or $9 \mathrm{~h}: 600 \mu \mathrm{mol} \cdot \mathrm{m}^{-2} \cdot \mathrm{s}^{-1}$ photosynthetic photon flux. Temperature was $28 / 22^{\circ} \mathrm{C}$ light/dark with a relative humidity of $70 \% \pm 5 \%$. Storage root and foliage yields were greater in both cultivars exposed to a longer daily light period and lower irradiance. The main effect of cultivar indicated that storage root yield was significantly greater among plants of 'Whatley/Loretan' compared with that of 'Georgia Jet', whereas foliage yield was similar between cultivars. Leaves of plants grown under longer daily light period and lower irradiance had significantly lower concentrations of all elements, nitrogen, phosphorus, potassium, calcium, magnesium, manganese, iron, calcium, boron, and zinc, except for calcium, manganese, and boron. There were no significant differences in leaf elemental concentration between cultivars. Thus, a longer daily light and lower irradiance enhanced biomass production of sweetpotato but reduced leaf elemental concentration probably because of a "dilution" effect.
\end{abstract}

Sweetpotato [Ipomoea batatas (L.) Lam] is a herbaceous, perennial plant that is grown mainly for its edible storage roots, although the leaves and tips are consumed as a green vegetable (Villareal, 1982; Woolfe, 1992). The storage roots are high in carbohydrates, beta-carotene (orange-fleshed cultivars), vitamins $\mathrm{B} 1$ (thiamine) and $\mathrm{C}$, iron $(\mathrm{Fe})$, and phosphorus (P) and dietary fiber (Hill et al., 1989; Woolfe, 1992). The leaves are high in vitamins B2 (riboflavin), Fe, and P. Because of its versatility, high energy concentration, nutritional composition, and the potential of using the tender shoots as a green vegetable, the crop is among the list of staple and vegetable crops selected by the National Aeronautics and Space Administration (NASA) to

\footnotetext{
Received for publication 1 Dec. 2008. Accepted for publication 14 May 2009.

Contribution of the George Washington Carver Agricultural Experiment Station, Tuskegee University.

This research was supported by funds from the U.S. National Aeronautics and Space Administration (Grant No. NCC9-158 and USDA/CSREES Grant No. ALX-SP-1).

${ }^{1}$ Research Professor.

${ }^{2}$ Former Graduate Student.

${ }^{3}$ Professor.

${ }^{4}$ To whom reprint requests should be addressed; e-mailmortleyd@tuskegee.edu.
}

provide food for space travelers on extended missions (Salisbury and Clark, 1996; Tibbitts and Alford, 1982; Waters et al., 2002).

The absorption of light by plants is a component in regulating plant growth and development. In addition to irradiance, daily light period also influences the growth and yield of sweetpotatoes. As part of the Exploration Life Support System program, NASA testing has focused on light period responses of candidate species, the rationale being that if plant growth and storage root yield could be increased with longer daily light periods, the total crop area required to sustain humans in a life support system could be reduced (Wheeler, 2006).

Porter (1979) reported greater storage root yield and McDavid and Alamu (1980) reported that longer light periods at similar total irradiance promoted leaf expansion and larger leaf area among plants grown at light periods between 11.5 and $12.5 \mathrm{~h}$ compared with 8 -h or 18 -h periods. In contrast, Biswas and Mukhopadhay (1989) reported significant increases in the number of storage roots among plants exposed to short light periods $(9 \mathrm{~h})$, whereas vine yields were greater under longer daily light periods (16 h). Bonsi et al. (1992) grew sweetpotatoes under 24-h or 12greater biomass production with continuous $\mathrm{h}$ light periods in soilless culture and reported light compared with plants grown at 12-h light periods, which had fewer but larger leaves. Previous studies on the interaction of irradiance and $\mathrm{N}: \mathrm{K}$ ratio on sweetpotato responses have shown that irradiance exerted a greater effect in increasing storage root yield than did N:K ratio (Mortley et al., 1993).

Although longer light periods have enhanced storage root yield and some cultivars are more sensitive than others (Mortley et al., 1996), the question still remains as to whether enhanced growth responses are the result of increased daily light period or the increase in the number of photosynthetic photons to which the plants are exposed irrespective of daylength effects.

Our objective was to evaluate the effect of irradiance and daily light period on storage root yield and leaf elemental concentration of two sweetpotato cultivars grown hydroponically using the nutrient film technique (NFT).

\section{Materials and Methods}

Experiments were conducted in a randomized complete block design with three replications in time in four reach-in controlled environment growth chambers (Percival Scientific Inc., Boone, IA), and each run lasted $120 \mathrm{~d}$. Four stem cuttings $(15 \mathrm{~cm})$ from each of two cvs., Whatley/Loretan and Georgia Jet, were planted into each of two NFT channels $(0.15 \times 0.15 \times 1.2 \mathrm{~m})$ in each growth chamber $25 \mathrm{~cm}$ apart through holes $(2.5 \mathrm{~cm}$ diameter) in a polyvinyl chloride-1 flat plate assembly and $25 \mathrm{~cm}$ between channels (Mortley et al., 1991). Stem cuttings were obtained from propagation beds maintained in the greenhouse.

Treatments consisted of an 18-h light period in combination with a photosynthetic photon flux $(P P F)$ of $300 \mu \mathrm{mol} \cdot \mathrm{m}^{-2} \cdot \mathrm{s}^{-1}$ or a 9-h light period at $600 \mu \mathrm{mol} \cdot \mathrm{m}^{-2} \cdot \mathrm{s}^{-1}$ such that plants received an identical daily light integral $\left(19.4 \mathrm{~mol} \cdot \mathrm{m}^{-2} \cdot \mathrm{s}^{-1}\right)$. Light was supplied by a mixture of cool white fluorescent and incandescent lamps and irradiance levels were monitored weekly through the use of a LI-COR 185 B quantum radiometer/photometer (LI-COR, Lincoln, NE). Temperature was maintained at $28 / 22{ }^{\circ} \mathrm{C}$ and relative humidity was monitored with a psychrometer and maintained at $70 \% \pm 5 \%$. Carbon dioxide concentration was at laboratory ambient (400 $\mu \mathrm{mol} \cdot \mathrm{mol}^{-1}$ ).

A modified half-strength Hoagland's nutrient solution (Hoagland and Arnon, 1950) with a 1:2.4 N:K ratio was used. The solution was replenished once per week based on electrical conductivity (EC) by adding deionized water to volume after which EC was adjusted to $1200 \mu \mathrm{S}^{-1}$ with a concentrated Hoagland stock. Solution $\mathrm{pH}$ was maintained between 5.5 and 6.0 at each replenishment by adjusting with dilute $\mathrm{NaOH}$ or $\mathrm{HCl}$. The solution was supplied to the plants in each channel from 30.4-L reservoirs with in-line pumps (Little Giant Pump Co., Oklahoma City, OK). Growth channels were on a $1 \%$ slope to facilitate return of the nutrient solution to the reservoir by gravity flow. 
Leaf samples, consisting of the fourth fully expanded leaf from the terminals of the vines, were collected at $4,8,12$, and 16 weeks after planting. Samples for the four plants of each cultivar were combined into one composite sample and dried at $70{ }^{\circ} \mathrm{C}$ for $48 \mathrm{~h}$. Dried samples were ground using a mortar and pestle and analyzed for nitrogen $(\mathrm{N})$, $\mathrm{P}$, potassium $(\mathrm{K})$, calcium $(\mathrm{Ca})$, magnesium $(\mathrm{Mg})$, manganese $(\mathrm{Mn}), \mathrm{Fe}$, copper $(\mathrm{Cu})$, boron $(\mathrm{B})$, and zinc $(\mathrm{Zn})$ by the Plant and Soil Testing Laboratory at Auburn Univ. (Hue and Evans, 1986). To substantiate that yield increases under the longer daily light periods were the result of increased daylength and not the total number of integrated photons, the treatments were reversed. A 9or 18-h light period was combined with 300 or $600 \mu \mathrm{mol} \cdot \mathrm{m}^{-2} \cdot \mathrm{s}^{-1}$, respectively.

Plants were harvested 120 days after planting weighed fresh and after drying for $72 \mathrm{~h}$ at $70{ }^{\circ} \mathrm{C}$. Storage root fresh weights were determined and a $25 \mathrm{-g}$ sample of each root from each plant was dried at $70{ }^{\circ} \mathrm{C}$ for $48 \mathrm{~h}$. This information was used to calculate a fresh-to-dry weight conversion factor to estimate storage root dry weight. Harvest index (root dry weight $\div$ total plant dry weight $\times$ 100) was calculated. The experiment was repeated three times and all data were analyzed by an analysis of variance using the General Linear Models Procedure (SAS Institute, 1996).

\section{Results and Discussion}

Only main effects are presented because there were no significant light period $x$ irradiance interactions. Plants that were exposed to the longer light period and lower irradiance produced greater storage root biomass compared with plants grown at a shorter light period and higher irradiance (Table 1). Storage root yields were $59 \%$ greater under the longer light period. Similar results were reported by others (Bonsi et al., 1992; McDavid and Alamu, 1980; Porter, 1979), all of whom reported greater storage root yield under longer light periods. Although foliage fresh weight was greater, dry mass was not significantly influenced by the light period/ irradiance combination. Harvest index was significantly greater among plants grown under a longer light period and lower irradiance.

Cultivars significantly influenced storage and fibrous root production and harvest index but exerted very little impact on foliage yield (Table 2). 'Whatley-Loretan' produced 33\% and $36 \%$ greater storage root fresh and dry mass, respectively, than 'Georgia Jet', whereas fibrous root dry mass was significantly greater for 'Georgia Jet' when averaged across treatments. The effects of either light period/irradiance or cultivar did not significantly influence percent dry matter. Generally, root growth of cultivars responded differently to the treatments in that 'WhatleyLoretan' produced higher storage root yield at the expense of fibrous root production.

The effect of light period/irradiance on elemental leaf concentration is shown in
Table 3. Leaves of plants exposed to longer light periods and lower irradiance had significantly lower concentrations of all elements, $\mathrm{N}, \mathrm{P}, \mathrm{K}, \mathrm{Ca}, \mathrm{Mg}, \mathrm{Mn}, \mathrm{Fe}, \mathrm{Cu}, \mathrm{B}$, and $\mathrm{Zn}$, except for $\mathrm{Ca}, \mathrm{Mg}, \mathrm{Mn}$, and $\mathrm{B}$, which were similar between treatments. There were no significant differences between cultivars with respect to elemental leaf concentration (data not shown). Therefore, when viewed in the context of the results in Table 3 , these results suggest that the response of the cultivars in relation to elemental concentration was attributable in part to the treatment and not to inherent cultivar differences. Mills and Jones (1996) showed that light affects the concentration of elements in plants by directly influencing the amount of photosynthates produced, thereby altering the ratio of element to dry matter concentration. In addition, the lower elemental concentration

Table 1. The effects of light period and photosynthetic photon flux $(P P F)$ on storage, fibrous roots, and foliage yield of hydroponically grown sweetpotato.

\begin{tabular}{lrcc}
\hline & \multicolumn{3}{c}{ Light period $/ P P F\left(\mathrm{~h} / \mu \mathrm{mol} \cdot \mathrm{m}^{-2} \cdot \mathrm{s}^{-1}\right)$} \\
\cline { 2 - 4 } Growth responses & $18 / 300$ & $9 / 600$ & $P$ values \\
\hline Storage root & 25.8 & 18.2 & 0.04 \\
$\quad$ No. per $\mathrm{m}^{2}$ & $2,671.0$ & $1,680.0$ & 0.0001 \\
$\quad$ Fresh weight $\left(\mathrm{g} \cdot \mathrm{m}^{-2}\right)$ & 382.2 & 220.0 & 0.0001 \\
$\quad$ Dry mass $\left(\mathrm{g} \cdot \mathrm{m}^{-2}\right)$ & 14.0 & $13.2 \mathrm{NS}$ & \\
$\quad$ Dry matter $(\%)$ & 29.8 & 21.8 & 0.0001 \\
Fibrous root & & & \\
$\quad$ Dry mass $\left(\mathrm{g} \cdot \mathrm{m}^{-2}\right)$ & $2,449.0$ & $2,044.0$ & 0.02 \\
Foliage & 220.0 & 187.1 & $\mathrm{NS}$ \\
$\quad$ Fresh weight $\left(\mathrm{g} \cdot \mathrm{m}^{-2}\right)$ & 60.4 & 51.2 & 0.05 \\
$\quad$ Dry mass $\left(\mathrm{g} \cdot \mathrm{m}^{-2}\right)$ & & & \\
Harvest index & & &
\end{tabular}

${ }^{2}$ Significant at 0.05 or NS $=$ nonsignificant.

Table 2. The effects of cultivar on storage, fibrous roots, and foliage yield of hydroponically grown sweetpotato.

\begin{tabular}{lrcc}
\hline & & Cultivar & \\
\cline { 2 - 4 } Growth responses & Whatley/Loretan & Georgia Jet & $P$ values \\
\hline Storage root & & & \\
$\quad$ No. per $\mathrm{m}^{2}$ & 24.9 & 19.6 & $\mathrm{NS}$ \\
Fresh weight $\left(\mathrm{g} \cdot \mathrm{m}^{-2}\right)$ & $2,484.0$ & $1,867.0$ & 0.0001 \\
$\quad$ Dry mass $\left(\mathrm{g} \cdot \mathrm{m}^{-2}\right)$ & 137.1 & 255.1 & 0.01 \\
$\quad$ Dry matter $(\%)$ & & 13.9 & NS \\
Fibrous root & 16.9 & 34.7 & 0.0001 \\
$\quad$ Dry mass $\left(\mathrm{g} \cdot \mathrm{m}^{-2}\right)$ & & & \\
Foliage & $2,218.0$ & $2,280.0$ & $\mathrm{NS}$ \\
$\quad$ Fresh weight $\left(\mathrm{g} \cdot \mathrm{m}^{-2}\right)$ & 209.8 & 196.9 & $\mathrm{NS}$ \\
$\quad$ Dry mass $\left(\mathrm{g} \cdot \mathrm{m}^{-2}\right)$ & 60.5 & 52.4 & 0.05 \\
Harvets index $(\%)$ & & &
\end{tabular}

${ }^{2}$ Significant at 0.05 or NS $=$ nonsignificant at 0.05 .

Table 3. The effects of light period and photosynthetic photon flux $(P P F)$ on elemental leaf concentration of hydroponically grown sweetpotato.

\begin{tabular}{lccc}
\hline & \multicolumn{3}{c}{ Light period $/ P P F\left(\mathrm{~h} / \mu \mathrm{mol} \cdot \mathrm{m}^{-2} \cdot \mathrm{s}^{-1}\right)$} \\
\cline { 2 - 4 } Growth responses & $18 / 300$ & $9 / 600$ & $P$ values \\
\hline Elements & 2.9 & 3.9 & 0.05 \\
Nitrogen (\%) & 0.5 & 0.7 & 0.05 \\
Phosphorus (\%) & 4.3 & 4.9 & 0.01 \\
Potassium (\%) & 0.9 & 1.1 & $\mathrm{NS}$ \\
Calcium $(\%)$ & 0.4 & 0.4 & $\mathrm{NS}$ \\
Magnesium $(\%)$ & 96.3 & 110.7 & $\mathrm{NS}$ \\
Manganese $\left(\mu \cdot \mathrm{g}^{-1}\right)$ & 63.3 & 86.3 & 0.0001 \\
Iron $\left(\mu \cdot \mathrm{g}^{-1}\right)$ & 3.7 & 7.2 & 0.0001 \\
Copper $\left(\mu \cdot \mathrm{g}^{-1}\right)$ & 47.7 & 51.8 & $\mathrm{NS}$ \\
Boron $\left(\mu \cdot \mathrm{g}^{-1}\right)$ & 30.0 & 42.1 & 0.01 \\
Zinc $\left(\mu \cdot \mathrm{g}^{-1}\right)$ & & & \\
\hline
\end{tabular}

${ }^{\mathrm{z}}$ Significant at 0.05 or NS $=$ nonsignificant at 0.05 . in the leaves of plants exposed to the longer light period and lower irradiance may have been the result of a "dilution" effect as evidenced by the greater storage root and foliage to or higher than the sufficiency levels for field-grown sweetpotatoes (Mills and Jones, 1996) or for hydroponically grown plants

physiological measurements such as leaf temperature, stomatal conductance, transpiration, and leaf area were not significantly leaves was $30 \%$ greater among plants grown at the shorter light period and higher irradiance (194) compared with that (135) among plants grown under the opposite treatment elemental concentrations were either equal 
Table 4. The effects of light period and photosynthetic photon flux $(P P F)$ on storage, fibrous roots, and foliage yield of hydroponically grown sweetpotato when the treatments were reversed.

\begin{tabular}{lrcc}
\hline & \multicolumn{3}{c}{ Light period $/ P P F\left(\mathrm{~h} / \mu \mathrm{mol} \cdot \mathrm{m}^{-2} \cdot \mathrm{s}^{-1}\right)$} \\
\cline { 2 - 4 } Growth responses & $18 / 600$ & $9 / 300$ & $P$ values \\
\hline Storage root & 16.4 & 1.8 & 0.0001 \\
$\quad$ No. per m $\mathrm{m}^{2}$ & $2,974.0$ & 41.8 & 0.0001 \\
Fresh weight $\left(\mathrm{g} \cdot \mathrm{m}^{-2}\right)$ & 459.1 & 15.8 & 0.0001 \\
$\quad$ Dry mass $\left(\mathrm{g} \cdot \mathrm{m}^{-2}\right)$ & 15.4 & 2.9 & 0.0001 \\
$\quad$ Dry matter $(\%)$ & & 13.8 & 0.0001 \\
Fibrous root & 42.2 & & 0.01 \\
$\quad$ Dry mass $\left(\mathrm{g} \cdot \mathrm{m}^{-2}\right)$ & & $1,295.0$ & 0.0001 \\
Foliage & $1,976.0$ & 117.3 & 0.05 \\
$\quad$ Fresh weight $\left(\mathrm{g} \cdot \mathrm{m}^{-2}\right)$ & 240.9 & 51.2 & \\
$\quad$ Dry mass $\left(\mathrm{g} \cdot \mathrm{m}^{-2}\right)$ & 60.4 & &
\end{tabular}

${ }^{\mathrm{z}}$ Significant at 0.05 or NS $=$ nonsignificant at 0.05 .

regime. This greater leaf number coupled with a lower leaf area (32.1 versus 40.1 $\mathrm{cm}^{2}$ ) is consistent with the findings of others (Bonsi et al., 1992; Kim, 1957; Mortley et al., 1996) and what we have observed consistently in experiments exposing plants to higher irradiance levels. Apparently, the plants compensate for the higher irradiance by producing a greater number of smaller leaves and shorter petioles. In addition, Hahn (1977) showed that sweetpotatoes could tolerate moderate shade by adopting certain morphological modifications, including fewer but longer leaves.

Although the impact of temperature was not a main focus of this study, temperature does influence storage root and foliage growth. Kim (1961) showed that storage root production was greatly enhanced under low night temperature $\left(29 / 20{ }^{\circ} \mathrm{C}\right)$ and low $P P F$ compared with a constant $29{ }^{\circ} \mathrm{C}$; foliage production was promoted by high night temperature. In our study, storage roots were produced with each treatment with daylength presumably exerting a strong influence.

Results of these studies involving the effects of light period and irradiance levels on the growth responses of hydroponically grown sweetpotato showed that yield increases under long daily light periods were the result of increased daylength and not integrated photosynthetic photons over time. For example, plants exposed to the longer light period and lower irradiance received a total of $19.4 \mathrm{~mol} \cdot \mathrm{m}^{-2} \cdot \mathrm{d}^{-1}$ total $P P F$ over $18 \mathrm{~h}$, whereas those plants exposed to the shorter light period received a similar total daily $P P F$ but over a shorter period. To substantiate that yield increase under the longer light period was not necessarily attributable in part to the total daily light integral, additional experiments were conducted in which the treatments were reversed. A 9-h light period was combined with a $P P F$ of $300 \mu \mathrm{mol} \cdot \mathrm{m}^{-2} \cdot \mathrm{s}^{-1}$ and an 18-h light period in combination with a $P P F$ of $600 \mu \mathrm{mol} \cdot \mathrm{m}^{-2} \cdot \mathrm{s}^{-1}$.

Results in Table 4 showed that plants exposed to the longer light period and higher $P P F$ produced significantly greater storage root number, yield, dry mass, percent dry matter, and foliage fresh and dry mass. There was very little or no storage root production among plants of either cultivar exposed to the shorter light period and lower $P P F$. These results are in agreement with those of Tsuno and Fujise (1965) who found that long-term reduction in daylength greatly decreased storage root growth with very little effect on foliage growth. Sekoika (1962) reported that more photosynthates were translocated to roots than to the leaves and upper stems at low than high $P P F$. Results from this study contrasted with those of Sekoika (1962) in that the root to shoot dry weight ratio was far lower (data not shown) under the shorter light period and lower $P P F$. This suggests that most of the photosynthates were not translocated to the storage roots but remained instead in the foliage. These results further suggest that sweetpotatoes grown under short light periods and low $P P F$ were mainly in a growth maintenance phase and favored foliage growth at the expense of storage root production. Bonsi et al. (1992) suggested that the increased yields obtained with 24-h compared with 12-h light periods were the result of a doubling of the number of photosynthetic photons irrespective of daylength effects. When integrated $P P F$ was doubled to 38.8 $\mathrm{mol} \cdot \mathrm{m}^{-2} \cdot \mathrm{d}^{-1}$, in our study, storage root fresh weight increased $11 \%$ and dry matter $20 \%$ and substantially lower under the 9-h light period $\left(9.72 \mathrm{~mol} \cdot \mathrm{m}^{-2} \cdot \mathrm{d}^{-1}\right)$ when the $P P F$ was reduced by three-fourths (Tables 1 and 4). Therefore, doubling PPF from 19.4 to 38.8 did not double storage root yield, but it suggests that the plants were still responding to increased daily $P P F$.

Therefore, the general implications of these results are 1) if sweetpotatoes are to be grown under long light periods such as $18 \mathrm{~h}$, lower $P P F$ can be used; and 2) if shorter light periods are to be used, then this will have to be compensated for by the use of higher $P P F$.

\section{Literature Cited}

Alexis, R. 1989. Nutrient deficiency symptoms in sweetpotatoes. MS Thesis, Tuskegee Univ.

Biswas, J.H. and S. Mukhopadhay. 1989. Effect of light hours on growth and tuber yield on sweetpotatoes. J. Root Crops 15:1920-1925.

Bonsi, C.K., P.A. Loretan, W.A. Hill, and D.G. Mortley. 1992. Response of sweetpotatoes to continuous light. HortScience 27:471.

Hahn, S.K. 1977. The sweetpotato, p. 237-248. In: Alvin, P.T. and T.T. Kolzwski (eds.). Ecophysiology of tropical crops. Academic Press, New York, NY.
Hill, W.A., P.A. Loretan, C.K. Bonsi, C.E. Morris, J.Y. Lu, and C. Ogbuehi. 1989. Utilization of sweetpotatoes in controlled ecological life support systems (CELSS). Adv. Space Res. 9:29-41.

Hoagland, D.R. and D.I. Arnon. 1950. The water culture method for growing plants without soil. Calif. Agr. Expt. Sta. Circ. 347.

Hue, N. and C.E. Evans. 1986. Procedures used by the Auburn University Soil Testing Laboratory. Auburn Univ. Agr. Expt. Sta. Ser. 16.

Kim, Y.C. 1957. Studies on the photoperiodic control for tuber formation in sweetpotato Korean J. Bot. 2:35-42.

Kim, Y.C. 1961. Effects of thermoperiodism on tuber formation in Ipomoea batatas under controlled conditions. Plant Physiol. 35:680684.

McDavid, C.R. and S. Alamu. 1980. Effect of day length on the growth and development of whole plants and rooted leaves of sweetpotato (Ipomoea batatas). Trop. Agr. (Trinidad) 57:113119.

Mills, H.A. and J.B. Jones. 1996. Plant analysis handbook. II: A practical sampling, preparation, analysis and intepretation guide. MicroMacro Publ. Inc., Athens, GA

Mortley, D.G., C.K. Bonsi, P.A. Loretan, W.A Hill, and C.E. Morris. 1993. Irradiance and nitrogen to potassium ratio influences sweetpotato yield in nutrient film technique. Crop Sci. 33:782-784.

Mortley, D.G., P.A. Loretan, C.K. Bonsi, W.A Hill, and C.E. Morris. 1991. Plant spacing influences yield and linear growth rate of sweetpotatoes grown hydroponically. HortScience 26:1274-1275.

Mortley, D.G., P.A. Loretan, W.A. Hill, C.K. Bonsi, and C.E. Morris. 1996. Growth responses of hydroponically grown sweetpotato tolerant and intolerant of a continuous daily light period. HortScience 31:209-212.

Porter, W.C. 1979. Sweetpotato growth as affected by photoperiod. HortScience 14:124.

Salisbury, F.B. and M.Z.A. Clark. 1996. Choosing plants to be grown in controlled environment life support system (CELSS) based upon attractive vegetarian diets. Life Support Biosph. Sci. 2:169-179.

SAS Institute. 1996. SAS user's guide: Statistics. Version 5. SAS Inst., Cary, NC.

Sekoika, H. 1962. The influence of light intensity on the translocation of sucrose-14C in the sweetpotato plant. Proc. Crop Sci. Soc. Japan $31: 159$

Tibbitts, T.W. and D.K. Alford. 1982. Controlled ecological life support system use of higher plants. NASA Conf. Pub 2231. NASA, Moffett Filed, CA

Tsuno, Y. and K. Fujise. 1965. Studies on the dry matter production of sweetpotato. Bull. Natl. Inst. Agr. Sci. (Japan) Series D No. 13.

Villareal, R.L. 1982. Sweetpotato in the tropics: Progress and problems, p. 3-16. In: Villareal, R.L. and T.D. Griggs (eds.). Sweetpotato. AVRDC Shanhua, Taiwan, China.

Waters, G.C.R., A. Olabi, J.B. Hunter, M.A. Dixon, and C. Lasseur. 2002. Bioregenerative food system cost based on optimized menus for advanced life support. Life Support Biosph. Sci. 2:199-210.

Wheeler, R.M. 2006. Potato and human exploration of space: Some observations from NASAsponsored controlled environment studies. Potato Res. 49:67-90.

Woolfe, A.J. 1992. Sweetpotato: An untapped food resource. Cambridge Univ. Press, New York, NY. 